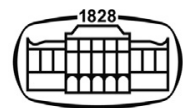

AKADÉMIAI KIADÓ

Journal of Psychedelic Studies

5 (2021) 1, 33-36

DOI:

10.1556/2054.2021.00167

(c) 2021 The Author(s)

ORIGINAL RESEARCH PAPER

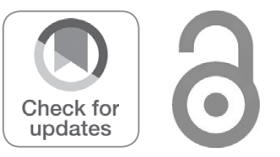

\title{
Have Norwegians tried psilocybin, and do they accept it as a medicine?
}

\section{HENRIK BØRSTING JACOBSEN ${ }^{1,2 *}$ (อ, AUDUN STUBHAUG ${ }^{2,3}$, BJØRN HOLMØY ${ }^{1}$, TOR MORTEN KVAM $^{4}$ and SILJE ENDRESEN REME ${ }^{1,2}$}

\author{
${ }^{1}$ Mind-Body Lab, Department of Psychology, University of Oslo, Norway \\ ${ }^{2}$ Department of Pain Management and Research, Division of Emergencies and Critical Care, Oslo \\ University Hospital, Oslo, Norway \\ ${ }^{3}$ Institute of Clinical Medicine, Faculty of Medicine, University of Oslo, Norway \\ ${ }^{4}$ PsykForsk, Østfold Hospital Trust, Norway
}

Received: December 23, 2020 • Accepted: March 30, 2021

Published online: April 15, 2021

\begin{abstract}
Background: Psilocybin is emerging as a promising therapeutic agent for a wide range of psychiatric conditions, and clinical trials on psilocybin-assisted treatment are forthcoming in Scandinavian countries. However, little is known about attitudes towards this psychedelic compound among the general public in Nordic countries. This might represent a confound, and reduce the validity of research findings or the overall feasibility of conducting high-quality clinical trials. Aims: The main objective of this study is to address the knowledge gap surrounding use and attitudes towards psilocybin in Norway. Methods: We asked a representative sample of the Norwegian population $(N=1,078)$ if they have ever tried psilocybin and if they would be willing to do so as part of medical treatment. These questions were part of a larger online survey on a variety personal preferences and attitudes, and the survey was not presented as a study on psilocybin. Results: Of the 1,078 respondents, $8 \%$ reported previous psilocybin use and $51 \%$ were willing to try psilocybin in medical treatment. Conclusions: Psilocybin use is more common in Norway than the authors hypothesized, and the general public is relatively open to using psilocybin in a medical context. The latter is interpreted as promising with regards to the feasibility of conducting rigorous clinical trials on potential effects and side effects of psilocybin-assisted treatment in Norway.
\end{abstract}

\section{KEYWORDS}

psilocybin, population study, mental health, psychedelic-assisted therapy

\section{INTRODUCTION}

Psilocybin, or 4-phosphoryloxy-N,N-dimethyltryptamine, is a hallucinogenic compound that is one of a few active constituents contained in a variety of mushrooms, most in the family psilocybe, referred to as "magic mushrooms". In recent years psilocybin has shown promising results in treatment-resistant depression, anxiety, cancer-related mental distress, as well as addiction (Andersen, Carhart-Harris, Nutt, \& Eritzoe, 2020). Multiple studies show how psilocybin can produce profound changes in thought, perception and emotion, facilitating transformative experiences (Kvam, Stewart, \& Andreassen, 2018; Griffiths, Richards \& Johnson, 2008).

Promising results from preliminary trials (e.g., Carhart-Harris, Bolstridge, Rucker et al., 2016) have caused the U.S. Food and Drug Administration (FDA) to position psilocybin as a "breakthrough therapy" for depression, meaning that they expedite the use and approval of clinical trials. In Scandinavian countries, the clinical testing of psilocybin as a treatment for depression has been forthcoming, sparking both public interest and criticism (Bamle, Lunde, \& Belgaux, 2020). 
Although population studies exist in the U.S. (e.g., Krebs \& Johansen, 2013), there is a huge knowledge gap regarding how psilocybin is viewed by the population in Scandinavian countries in general, and Norway specifically. Relative to comparable countries, Norway has traditionally led a more restrictive drug policy (Moeller, 2019), and psilocybin has been classified as an illegal drug since 1971. Therefore, one might reasonably question whether this context has created a bias towards skepticism to the use of psychedelic compounds in medical treatment.

After its classification as an illegal drug, the scientific study of psilocybin which had been quite prolific in the 1950s and 1960s were stopped across the board. Today, any successful use of psilocybin in research and medical care will rely to a certain extent on public approval and willingness to accept psychedelic drugs as a potential medicine. Particularly in the context of clinical trials where effects and side effects to a large extent are unknown. If acceptance is low in the general public, one risks that overly positive participants constitute the study sample, or that a lack of willing participants completely hampers recruitment. To date, there are no studies or data to judge these essential attitudes in Scandinavians, endangering scientific endeavors of putting the proverbial cart before the horse.

Thus, our main aim was to assess attitudes towards psilocybin among a representative sample of Norwegians by asking two important questions: (i) If they had ever tried psilocybin, and (ii) if they would consider testing psilocybin as a medicine.

Based on the discourse and legal status of psychedelics in Norway, we hypothesized that the number of people who had tried psilocybin would be much lower than similar figures reported in the U.S. We further hypothesized that Norwegians to a large extent would lack the desire or willingness to try psilocybin as part of any medical treatment.

\section{METHODS}

The project was carried out in the spring of 2020. The sample for this study was procured using Ipsos, a commercial provider of polling data. The sample was randomly drawn from Ipsos' online panel as a small part of a large questionnaire containing several different questions regarding political affiliation, income and other information relevant to the population sample. Avoiding any pre-selection, the survey was not presented as a survey on psilocybin, rather as a survey investigating a wide range of personal preferences and attitudes in the general population.

The Ipsos sample strategy uses quotas on gender, age and region, when drawing a sample, ensuring a representative distribution. After a sample has been obtained from the Ipsos online panel, it is de-identified before Ipsos calibrates respondent characteristics to be representative of the Norwegian population using standard procedures such as ranking-ratio adjustments. The source of these population targets is census data. The sample drawn for this study reflects fixed sample targets on demographics. Post-hoc weights were made to the population characteristics on gender, age, and geography to ensure a representative sample.

The project was approved by the Department of Psychology's internal research ethics committee at the University of Oslo (Ref: 6225156).

A representative sample of 1,078 Norwegians was presented a short text describing psilocybin: «Psychedelic drugs, such as psilocybin (magic mushrooms/liberty cap), are compounds that dramatically alter our mental state. Such compounds have been used in medicine and psychology since the 1960s, but within the last ten years there have been demonstrated particularly promising results when used for depression, anxiety and addiction.» before responding to the following two questions:

1. Have you ever tried psilocybin (magic mushrooms)? ("Yes", "No" or "Do not know").

2. How likely is it that you would have agreed to assisted psilocybin therapy performed by medical health professionals if your condition could have benefited from it? ("Very likely", "Pretty likely", "A bit likely", "Not likely at all" or "Do not know").

\section{Statistical analyses}

In initial analyses, demographics was reported for the two items as frequency and percentage. To investigate the association between demographical information and the response on the two items, we performed a correlation matrix to show significant correlations between demographic characteristics and response. Significance level was set at $P<0.05$ and analyses were performed in SPSS version 25 .

\section{RESULTS}

In this representative sample of Norwegians, $8 \%(n=86)$ had tried psilocybin, $2 \%(n=23)$ indicated that they did not know, and $90 \%(n=969)$ had not tried it (see Table 1$)$. When asked whether they would consider psilocybin as part of a medical treatment, 51\% $(n=549)$ responded "Very likely", "Pretty likely" or "A bit likely", $31 \%(n=331)$ responded "Not likely at all" and $18 \%(n=198)$ responded that they "did not know". Correlation matrixes showed that being young $\left(r^{2}=0.21, P<\right.$ $0.001)$, single (Number of people in household $\left(r^{2}=-0.07, P\right.$ $=0.04)$ ), and male $\left(r^{2}=0.07, P=0.03\right)$ living in a densely populated area $\left(r^{2}=0.11, P=0.001\right)$ was correlated with having tried psilocybin.

The same demographic descriptors were correlated with a positive attitude towards trying psilocybin as part of a medical treatment: young $\left(r^{2}=0.21, P<0.001\right)$, single (number of people in household $\left(r^{2}=-0.11, P=0.002\right)$ ) male $\left(r^{2}=0.11, P=0.002\right)$ in densely populated areas $\left(r^{2}=\right.$ $0.12, P<0.001)$. In addition, having tried psilocybin before was correlated to the willingness to try it as a medicine, but only moderately $\left(r^{2}=0.31, P<0.001\right)$. 
Table 1. Sample demographics of respondents categorized on how they answered two questions about use and attitudes towards psilocybin. Question 1 (Q1) "Have you ever tried psilocybin (magic mushrooms)?" was rated yes/no. Question 2 (Q2) "How likely is it that you would have agreed to assisted psilocybin therapy performed by medical health professionals if your condition could have benefited from it?" had was dichotomized from 5 possible responses ("Very likely", "Pretty likely", "A bit likely", "Not likely at all" or "Do not know") into "likely" or "not likely" to illustrate differences on demographics in a clear and succinct way

\begin{tabular}{|c|c|c|c|c|}
\hline & $\begin{array}{l}\text { Q1 Yes } \\
N=86\end{array}$ & $\begin{array}{c}\text { Q1 No } \\
N=969\end{array}$ & $\begin{array}{l}\text { Q2 Likely } \\
N=549\end{array}$ & $\begin{array}{c}\text { Q2 Not likely } \\
N=331\end{array}$ \\
\hline & $N(\%)$ & $N(\%)$ & $N(\%)$ & $N(\%)$ \\
\hline \multicolumn{5}{|l|}{ Gender } \\
\hline Male & $52(60.5 \%)$ & $467(48.2 \%)$ & $296(53.9 \%)$ & $145(43.8 \%)$ \\
\hline Female & $34(39.5 \%)$ & $502(51.8 \%)$ & $253(46.1 \%)$ & $186(56.2 \%)$ \\
\hline \multicolumn{5}{|l|}{ Age } \\
\hline $18-29$ years & $34(39.5 \%)$ & $183(18.9 \%)$ & $140(25.5 \%)$ & $51(15.4 \%)$ \\
\hline $30-39$ years & $25(29.1 \%)$ & $152(15.7 \%)$ & $108(19.7 \%)$ & $44(13.3 \%)$ \\
\hline $40-49$ years & $14(16.3 \%)$ & $168(17.3 \%)$ & $104(19 \%)$ & $46(13.9 \%)$ \\
\hline $50-59$ years & $11(12.8 \%)$ & $164(16.9 \%)$ & $85(15.5 \%)$ & $58(17.5 \%)$ \\
\hline $60-69$ years & $2(2.3 \%)$ & $144(14.9 \%)$ & $65(11.8 \%)$ & $54(16.3 \%)$ \\
\hline $70-79$ years & $0(0 \%)$ & $136(14 \%)$ & $38(6.9 \%)$ & $71(21.5 \%)$ \\
\hline $80-91$ years & $0(0 \%)$ & $22(2.3 \%)$ & $9(1.6 \%)$ & $7(2.1 \%)$ \\
\hline \multicolumn{5}{|l|}{ Education } \\
\hline Primary & $1(1.2 \%)$ & $13(1.4 \%)$ & $6(1.1 \%)$ & $4(1.2 \%)$ \\
\hline Lower secondary & $12(14 \%)$ & $65(6.7 \%)$ & $46(8.4 \%)$ & $22(6.7 \%)$ \\
\hline Upper secondary & $34(39.5 \%)$ & $315(32.5 \%)$ & $179(32.6 \%)$ & $104(31.4 \%)$ \\
\hline College/University less than 4 years & $21(24.4 \%)$ & $384(39.6 \%)$ & $210(38.2 \%)$ & $140(42.3 \%)$ \\
\hline College/University more than 4 years & $18(20.9 \%)$ & $192(19.8 \%)$ & $108(19.7 \%)$ & $61(18.4 \%)$ \\
\hline$<300.000 \mathrm{kr}$. & $26(30.2 \%)$ & $76(7.8 \%)$ & $66(12.1 \%)$ & $25(7.6 \%)$ \\
\hline $300.000-499.999 \mathrm{kr}$ & $23(26.7 \%)$ & $139(14.3 \%)$ & $94(17.1 \%)$ & $44(13.3 \%)$ \\
\hline $500.000-799.000 \mathrm{kr}$ & $20(23.3 \%)$ & $226(23.3 \%)$ & $117(21.3 \%)$ & $89(26.9 \%)$ \\
\hline $800.000-999.999 \mathrm{kr}$ & $6(7 \%)$ & $152(15.7 \%)$ & $88(16 \%)$ & $43(13.0 \%)$ \\
\hline 1 M.-1.5 M. kr & $6(7 \%)$ & $133(13.7 \%)$ & $77(14 \%)$ & $42(12.7 \%)$ \\
\hline$>1.5 \mathrm{M} . \mathrm{kr}$ & $1(1.2 \%)$ & $50(5.2 \%)$ & $22(4 \%)$ & $15(4.5 \%)$ \\
\hline Not given & $4(4.6 \%)$ & $193(20 \%)$ & $85(15.5 \%)$ & $73(22.0 \%)$ \\
\hline \multicolumn{5}{|l|}{ Political affiliation } \\
\hline Progress party & $14(16.3 \%)$ & $107(11 \%)$ & $61(11.1 \%)$ & $43(13.0 \%)$ \\
\hline Conservative party & $18(20.9 \%)$ & $185(19.1 \%)$ & $102(18.6 \%)$ & $72(21.8 \%)$ \\
\hline Liberal party & $1(1.2 \%)$ & $19(2 \%)$ & $11(2 \%)$ & $4(1.2 \%)$ \\
\hline Christian democratic party & $2(2.3 \%)$ & $19(2 \%)$ & $8(1.5 \%)$ & $9(2.7 \%)$ \\
\hline Green party & $3(3.5 \%)$ & $45(4.6 \%)$ & $33(6 \%)$ & $7(2.1 \%)$ \\
\hline Centre party & $5(5.8 \%)$ & $94(9.7 \%)$ & $49(8.9 \%)$ & $38(11.5 \%)$ \\
\hline Labour party & $15(17.4 \%)$ & $158(16.3 \%)$ & $87(15.8 \%)$ & $53(16.0 \%)$ \\
\hline Socialist left party & $5(5.8 \%)$ & $65(6.7 \%)$ & $43(7.8 \%)$ & $17(5.1 \%)$ \\
\hline Red party & $10(11.6 \%)$ & $62(6.4 \%)$ & $47(8.6 \%)$ & $22(6.6 \%)$ \\
\hline Not given & $13(15.2 \%)$ & $215(22.2 \%)$ & $108(19.7 \%)$ & $66(19.6 \%)$ \\
\hline \multicolumn{5}{|l|}{ County } \\
\hline Viken & $13(15.1 \%)$ & $257(26.5 \%)$ & $131(23.8 \%)$ & $98(29.6 \%)$ \\
\hline Vestfold og Telemark & $9(10.5 \%)$ & $75(7.7 \%)$ & $47(8.6 \%)$ & $19(5.7 \%)$ \\
\hline Agder & $2(2.3 \%)$ & $49(5.1 \%)$ & $21(3.8 \%)$ & $19(5.7 \%)$ \\
\hline Rogaland & $9(10.5 \%)$ & $57(5.9 \%)$ & $41(7.5 \%)$ & $15(4.5 \%)$ \\
\hline Vestland & $10(11.7 \%)$ & $101(10.4 \%)$ & $61(11.1 \%)$ & $34(10.3 \%)$ \\
\hline Møre og Romsdal & $5(5.8 \%)$ & $35(3.6 \%)$ & $19(3.5 \%)$ & $15(4.5 \%)$ \\
\hline Trøndelag & $2(2.3 \%)$ & $78(8 \%)$ & $39(7.1 \%)$ & $21(6.4 \%)$ \\
\hline Nordland & $2(2.3 \%)$ & $50(5.2 \%)$ & $25(4.6 \%)$ & $22(6.7 \%)$ \\
\hline Troms og Finnmark & $7(8.1 \%)$ & $31(3.2 \%)$ & $21(3.8 \%)$ & $15(4.5 \%)$ \\
\hline \multicolumn{5}{|l|}{ Region } \\
\hline Eastern Norway & $49(57 \%)$ & $568(58.6 \%)$ & $322(58.7 \%)$ & $190(57.4 \%)$ \\
\hline Southern Norway & $2(2.3 \%)$ & 49 (5.1\%) & $21(3.8 \%)$ & $19(5.8 \%)$ \\
\hline Western Norway & $24(27.9 \%)$ & $193(19.9 \%)$ & $121(22 \%)$ & $64(19.3 \%)$ \\
\hline Central Norway & $2(2.3 \%)$ & $78(8 \%)$ & $39(7.1 \%)$ & $21(6.3 \%)$ \\
\hline Northern Norway & $9(10.5 \%)$ & $81(8.4 \%)$ & $46(8.4 \%)$ & $37(11.2 \%)$ \\
\hline
\end{tabular}

\section{DISCUSSION}

When evaluating our hypotheses in the current sample, two findings were of particular interest. First, that the number of Norwegians who had actually tried psilocybin was $8 \%$, which was closer than we expected to the $13.4 \%$ reported in American population data (Krebs \& Johansen, 2013). This was somewhat surprising as psychedelic drugs have been considered particularly dangerous drugs in Norway (Haave \& Pedersen, 2020), while psilocybin is regarded as a popular recreational drug in the U.S. (Krebs \& Johansen, 2013). The latter exemplified by the recent legalization of psilocybin in the state of Oregon by popular vote, as well as decriminalization through ballot measures in multiple cities in the U.S. Our results indicate a skewed perception of use in Norway, with psilocybin use being more prevalent in the general population than we expected. Not surprisingly, age, civil status and living in an urban area were substantially correlated with having tried psilocybin. It was however somewhat surprising that political ideology, income or geographical location were not.

The second finding was the participants' overall willingness to try the drug in medical treatment. Over half of the nearly 1,100 respondents were willing to try this. We don't 
have data that shed light on why the respondents displayed such relative openness to psilocybin-assisted treatment, but one possibility is that Norwegians are generally more trustful towards their health care services than in many other countries (Jen, Sund, Johnston, \& Jones, 2010). This might entail that people who would otherwise not consider recreational psychedelic use are open to trying psilocybin in a treatment setting with a health care provider. Respondents in our study might have been influenced by the positive framing of psilocybin in the description preceding the questions, in which research findings about efficacy for certain conditions are highlighted. However, we consider this a reasonable and realistic description to provide to potential patients before a clinical trial or treatment. It is also possible that the general public is not as skeptical towards psychedelic substances as we assumed. The new wave of research on these compounds have generated great interest in the media and popular culture regarding possible benefits and relative safety of use in therapeutic contexts (e.g., Pollan, 2019). In addition, it is likely that psilocybin is regarded as less controversial than LSD, which was the most infamous drug in the backlash on psychedelics in research and treatment in the 1960s and 70s (Haave \& Pedersen, 2020).

In combination, these findings bode well for future trials of psilocybin in Norwegian populations, setting the scene for large clinical trials into the effects, and possible side effects, of this psychedelic drug. In line with this, our research group is currently planning a clinical trial on psilocybin-assisted treatment for persistent and complex pain, which constitute a patient group who experience insufficient relief from current treatment modalities.

\section{REFERENCES}

Andersen, K., Carhart-Harris, R., Nutt, D. J., \& Erritzoe, D. (2020). Therapeutic effects of classic serotonergic psychedelics: A systematic review of modern-era clinical studies. Acta Psychiatrica
Scandinavica. Advance online publication. https://doi.org/10. 1111/acps.13249.

Bamle P., Lunde A. F., \& Belgaux C. (2020) Our psychedelic future. Morgenbladet, pp. 14-16.https://morgenbladet.no/aktuelt/2020/01/ var-psykedeliske-fremtid?fbclid=IwAR0KxItng0s68X23cIChd9 DCMi2SSUzAh9VUF9DVstGEGPtr8hUYGzmhRV8.

Carhart-Harris, R. L., Bolstridge, M., Rucker, J., Day, C. M., Erritzoe, D., Kaelen, M., et al. (2016). Psilocybin with psychological support for treatment-resistant depression: An openlabel feasibility study. The Lancet. Psychiatry, 3(7), 619-627. https://doi.org/10.1016/S2215-0366(16)30065-7.

Griffiths, R., Richards, W., Johnson, M., McCann, U., \& Jesse, R. (2008). Mystical-type experiences occasioned by psilocybin mediate the attribution of personal meaning and spiritual significance 14 months later. Journal of Psychopharmacology, 22(6), 621-632. https://doi.org/10.1177/0269881108094300.

Haave, P. \& Pedersen, W. (2020). The Promise and Demise of LSD Psychotherapy in Norway. Social history of medicine. https:// doi.org/10.1093/shm/hkz128.

Jen, M. H., Sund, E. R., Johnston, R., \& Jones, K. (2010). Trustful societies, trustful individuals, and health: An analysis of selfrated health and social trust using the World Value Survey. Health \& Place, 16(5), 1022-1029. https://doi.org/10.1016/j. healthplace.2010.06.008.

Krebs, T. S., \& Johansen, P. Ø. (2013). Psychedelics and mental health: A population study. PloS One, 8(8), e63972. https://doi. org/10.1371/journal.pone.0063972.

Kvam, T. M., Stewart, L. H., \& Andreassen, O. A. (2018). Psychedelic drugs in the treatment of anxiety, depression and addiction. Psykedeliske stoffer i behandling av angst, depresjon og avhengighet. Tidsskrift for den Norske laegeforening, 138(18), PMID: 30421744. https://doi.org/10.4045/tidsskr.17.1110.

Moeller K. (2019). Sisters are never alike? Drug control intensity in the Nordic countries. The International Journal on drug Policy, 73, 141-145. https://doi.org/10.1016/j.drugpo.2019.06.004.

Pollan M. (2019). How to change your mind: What the new science of psychedelics teaches us about consciousness, dying, addiction, depression, and transcendence. Penguin Books. 